\title{
Preparability research on metasomatic ores and rocks of "Vostok-2" deposit
}

\author{
Luiza Samatova ${ }^{1 *}$ and Elena Shepeta ${ }^{1}$ \\ ${ }^{1}$ Mining Institute of Far eastern branch of Russian Academy of Sciences. Khabarovsk, Russia
}

\begin{abstract}
The research for examination of elemental composition of typical metasomatic rocks and ores have been carried out According to the data of mineral and petrographic analysis of twenty transparent sections in parallel and crossed Nicols, specific associations of minerals in ore of current production at "Vostochnyi" mine have been determined. Flotation testing on beneficiation of tailings of core geological samples has been conducted. Substantial redistribution of valuable mineral from easy ores to diluting rocks has been noted. The percent of greisen ore, with coarse scheelite grains, has become extremely rare and on the average is $2-2.5 \%$ of gross mass of scheelite-quartz ore. The appearance of skarn minerals relicts and, at times, areas of skarn minerals in scheelite-sulphide ores leads to formation, in the near-vein spaces, of scheelite-biotite, scheeliteamphibole, scheelite-piroxene, scheelite-chlorite and scheelite-mica complex associations. Impregnations of scheelite have been found in quartzous rocks, the composition of mother rocks may be diverse (skarn, skarnified or biotite hornfels, quartzites). The number of dispersed single scheelite grains in rock and anhedral grains in near-vein spaces adjacent to veins with high scheelite concentration has grown. The content of $\mathrm{CaCO}_{3}$ which is conditioned by the presence of Ca-containing minerals in the composition of skarn in the shape of thin (fine) grain crystalline impregnation along the crevices and cleavage faces with formation of thin microveinlets, often together with quartz has increased. The calculation of expected extraction has evaluated the drop of scheelite extraction from feed of Primorskaia ore-processing plant in saleable concentrate of down to $3 \%$. Key words: elemental composition, minerals association, idiomorphic and xenomorphic crystals, the calculation of expected extraction by ore types, flotation
\end{abstract}

\section{Introduction}

Scheelite skarn deposit — "Vostok-2" - refers to the main genetic type of tungsten deposits widely mined in Russia. In global balance, these deposits account for about $65 \%$ of ore production, whilst reserves amount to not more than 30\% (S.G. Solovev, 1997) [1]. Ore bodies of the deposit are represented by steep layer-by-layer pods situated along junctions of marbles and metamorphized diabase porphyrites [2].

\footnotetext{
${ }^{*}$ Corresponding author: samatova luiza@mail.ru
} 
Currently, in the global preparation practice, the expansion of resource base of tungsten takes place towards the searches and mining of deposits which are large by reserves, but with low content of $\mathrm{WO}_{3} 0.15-0.20 \%$ [King Island (Australia), Ferbertal (Austria), Salo (France), Kti-Teberd (North Caucasus), Kayrakty, Koktenkol (Central Kazakhstan), Skrytoe (Russia, Primorskii krai)], the involvement of dradge rock dumps and residue formations [3-9].

With the reduction of the content of valuable minerals in ore, particularly topical is the question of the efficiency of preparation and guarantee of raw material processing feasibility. Feasible mining of new low-grade deposits and residue formations may be reached by way of combined processing flow sheets with preliminary concentration of valuable components in the head ore with the use of radiometric methods of separation [1013]. However, currently scheelite-containing ores are processed at national plants as per traditional flotation technology where selective extraction of scheelite from finely disseminated ores is a difficult process task [14-17].

In order to define perspective directions with the increase in efficiency of main processes of flotation flow sheet for preparation, detailed study of elemental composition of ores, rocks and preparability evaluation are required.

\section{Research materials and methods}

In order to solve the task set, samples of ore, rocks and material from tailing of geological mapping cores of lower deposit levels have been selected.

Twenty transparent sections in parallel and crossed Nicols were studied by means of mineral and petrographic method; main associations of mineral, fineness and shape of scheelite grains were figured out.

Flotation benefication of ores and rocks were tested on samples weights with mass of 1 $\mathrm{kg}$. Time of size degradation were defined via distribution of scheelite in flotation grainsize class. The extraction of scheelite in the class $80+0 \mu \mathrm{m}$ corresponded with $84 \%$, including in sludge $(-44 \mu \mathrm{m}) 16 \%$.

Flotation tests have been performed using tap water in open and locked cycles.

Basic flotation scheme included sulphide and scheelite cycles, reagent schemes of bulk cycles were constant in all tests of given research. Main reagents of flotation sulphide cycles: sodium silicate (use rate (C)-5\%), dialkyldithiophosphate IMA-I413p (C-1\%), pine oil, sodium carbonate (C-10\%), sodium oleate of commercial acid B-115 (C-5\%).

Recovery (desorption cycle) of rough concentrates was performed by Petrov's method. The solid/liquid ratio was maintained as $1: 1$ in steaming, steaming duration in sodium silicate medium at the temperature of $80-85^{\circ} \mathrm{C}$ was 60 minutes. Selective flotation was performed after dilution with fresh water with poor flow of collectors.

\section{Experiments results and discussion}

Ore types defined, in current stage of deposit mining, have close positional connection, form gradual transitions of ones into others, and it is nearly impossible to outline larger blocks by types of ores and their selective mining.

Intervals of variations of thickness of various types of ores and rocks and contents of main valuable scheelite mineral (see table 1) are represented by core material (selection by 380 well-bore samples).

Materials with the range of content of $\mathrm{WO}_{3} 1.93-0.03 \%$ was studied for preparability in laboratory environment. 
The largest values for extraction were reached on quartz metasomatites and scheelitequartz-sulphide ore, the range of content is $0.08(0.25)-1.93 \%$. Scheelite was in these ores as local impregnation in quartz veins, quartz areas of hedenbergite skarns, on the boundary of quartz-sulphide. Less often, scheelite may be found in sulphides where grain size is less than $0.03-0.2 \mathrm{~mm}$, their shape is more roundish as if with melt-off corners and edges. Sometimes, big crystals of scheelite are crevassed; sulphides, quartz and calcite develop in crevices. Scarcely ever, but limestones lenses may be met in scheelite-quartz-sulphide ore. Then, the content of calcite rises from $5(8) \%$ to $45 \%$ which causes the complication of selection conditions and the drop of scheelite extraction into saleable concentrate from $92(90) \%$ to $67 \%$. In current production ores, percentage of rocks (biotite metasomatites, granodiorites, sandstones, quartzites) grew with the increase of scheelite content. In testing for preparability of biotite metasomatites with the content of scheelite of $0.8-1.9 \%$ (the content of calcite - $1-3.5 \%$ ), high level of extraction into saleable concentrate of 86.5 $91 \%$ is reached. The reduction of contents of down to $0.11-0.37 \%$ led to the extraction drop of down to $35-75 \%$.

Table 1. Distribution of ore and rocks in geological mapping cores

\begin{tabular}{|l|c|c|}
\hline \multirow{2}{*}{ Types and subtypes of ores and rocks } & $\begin{array}{c}\text { Layer } \\
\text { thickness, } \mathbf{~ m}\end{array}$ & WO3 content, \% \\
\cline { 2 - 3 } & \multicolumn{2}{|c|}{ Value, min-max } \\
\hline Scheelite-quartz and scheelite-sulphide ore & $0.4-9.5$ & $0.2-4.5\left(25^{*}\right)$ \\
Vein-disseminated ore and rocks, including: & & \\
Pyroxene skarn & $0.6-15$ & $0.10-1.5$ \\
Skarnified hornfels & $1.2-14.5$ & $0.02(0.17)-1.0$ \\
Biotite hornfels & $0.8-18.1$ & $0.01(0.11)-2.0$ \\
Quartz metasomatites & $1.0-11.8$ & $0.02(0.14)-0.9$ \\
Limestones & $0.5-7.5$ & $0.01-0.08$ \\
Granodiorites & $1.2-2.5$ & $0.01(0.15)-0.5$ \\
\hline Note: * Greisen ore present.
\end{tabular}

The increase of scheelite percent in rocks is connected, on one side, with the growth of number of favourable easy scheelite-sulphide veins with idiomorphic crystals. On the flip side, the quantity of dispersed single scheelite grains in the volume of rocks and anhedral grains in near-vein spaces adjacent to veins with high scheelite concentration, where complex associations of scheelite-biotite, scheelite-amphibole, scheelite-piroxene originate, grew up. Ore feed supplied to Primorskaia ore-processing plant for preparation has its valuable mineral percent redistributed by types as follows: from rich easy scheelite-quartz (skarn)-sulphide ore with $80 \%$ (the year of 2004) to $60 \%$ (the year of 2017), into rocks accordingly from $1 \%$ to $25 \%$.

The results of testing of clean types of ores and rocks for preparability are represented in fig. 1 . 


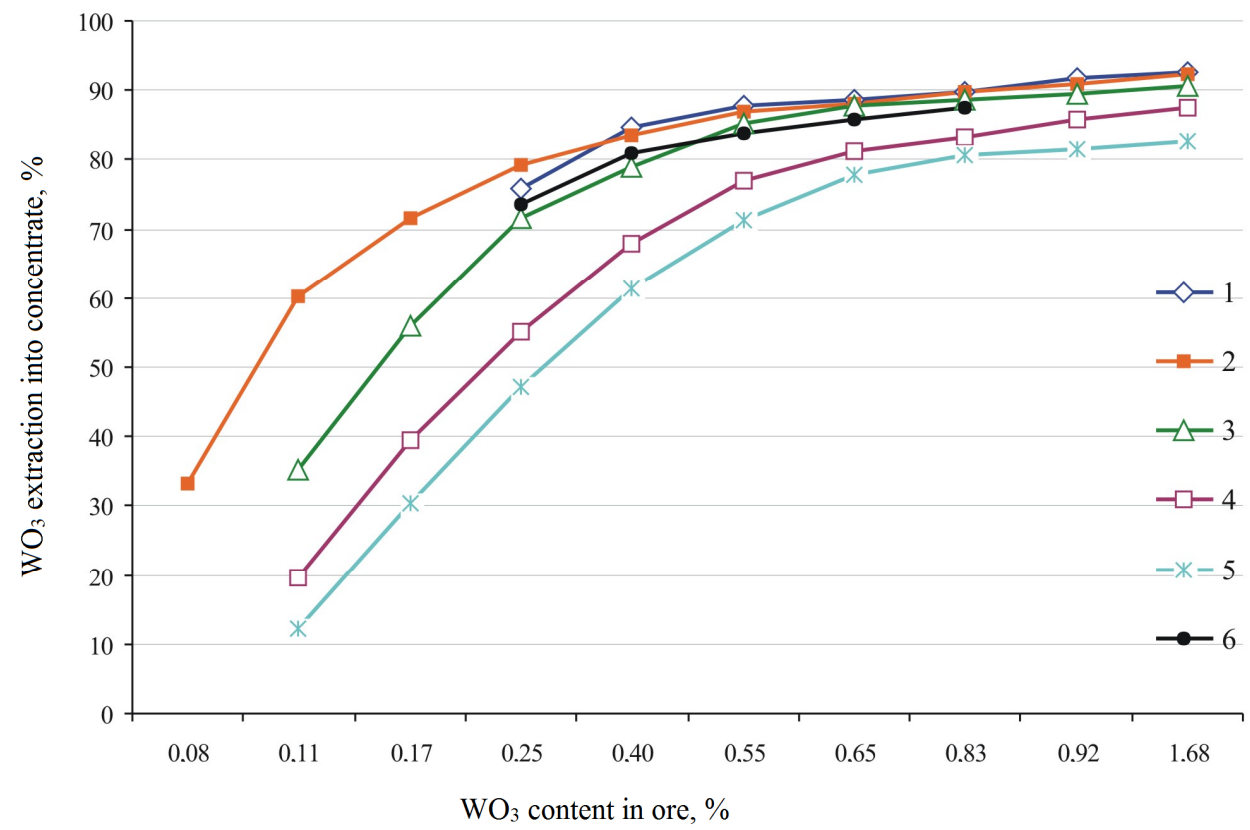

Fig. 1. The dependence of extraction of scheelite into saleable concentrate on the content of $\mathrm{WO}_{3}$ in various types of ores and rocks: 1 - scheelite-quartz-sulphide ore; 2 - quartz metasomatites; 3 - biotite hornfels; 4 - skarns; 5 - skarnified hornfels; 6 - feed of Primorskaia oreprocessing plant

The peculiarity of skarns and skarnified hornfels on lower levels of deposit mining is an increased content of calcites. Limestones lenses are met seldom, at that the degree of their marmorization is grown. The increase of $\mathrm{CaCO}_{3}$ content is conditioned by the presence of Ca-containing minerals in the composition of skarns in the shape of thin (fine) grain crystalline impregnation along the crevices and cleavage faces with formation of thin microveinlets, often together with quartz. The extraction of scheelite and obtainment of saleable concentrate significantly depends on the content of calcite in ore.

Scheelite mineralization in skarns is extremely non-uniform, basically poor, disperse content of $\mathrm{WO}_{3} 0.05-0.5 \%$, among which areas with thickness of $1-3$ meters with rich scheelite impregnation and the content of $\mathrm{WO}_{3} 1-5 \%$, seldom to $7-8 \%$, limited to intensively sulphidized and quartz zones, quartz-carbon-bearing veins and their vein walls, occur. Scheelite impregnation is $0.05-0.2(1.0) \mathrm{mm}$, idiomorphic crystals. In altered rocks (skarns, skarnified hornfels, quartzites) along veins and around local areas, scheelite occurs in the form of anhedral grains (the ratio between idiomorphic and xenomorphic scheelite $10: 1)$ with size of $0.01(0.02) \mathrm{mm}$ to $0.1(0.2) \mathrm{mm}$. The range of scheelite extraction from skarns and skarnified hornfels of $0(11.5)-88 \%$ is conditioned by the ratio of the contents of two Ca-containing minerals: scheelite and calcite.

The distribution of scheelite by ore types in the feed of Primorskaia ore-processing plant is represented in table 2 . 
Table 2. The distribution of scheelite and calculation of expected extraction

\begin{tabular}{|c|c|c|c|c|}
\hline $\begin{array}{l}\text { Ore } \\
\text { types }\end{array}$ & $\begin{array}{c}\text { shl-q, shl-q-s } \\
\left.\text { shl-q-(P } \text { P }_{x} \text { skarn }\right)-s\end{array}$ & $\begin{array}{c}\text { P }_{\mathbf{x}} \text { skarn, skarnified } \\
\text { (amf) hornfels, } q \\
\text { metasomatite }\end{array}$ & $\begin{array}{l}\text { bt metasomatite, } \\
\text { granodiorite, } \\
\text { sandstone }\end{array}$ & Feed \\
\hline $\begin{array}{c}\text { Period } \\
\text { of } \\
\text { analysis }\end{array}$ & $\begin{array}{l}\frac{\text { Output-content- }}{\text { distribution }} \\
\text { expected } \\
\text { extraction., } \%\end{array}$ & $\begin{array}{c}\text { Output-content- } \\
\text { distribution } \\
\text { expected extraction., } \\
\%\end{array}$ & $\begin{array}{c}\frac{\text { Output-content- }}{\text { distribution }} \\
\text { expected extraction., } \\
\%\end{array}$ & $\begin{array}{c}\text { Content, } \\
\text { extractio } \\
\text { n, } \%\end{array}$ \\
\hline 09.2017 & $\frac{15.26-3.95-74.16}{93.1}$ & $\frac{39.56-0.33-17.54}{71.6}$ & $\frac{46.18-0.14-8.30}{56.5}$ & $\frac{0.75}{86.3}$ \\
\hline 08.2017 & $\frac{17.09-2.96-75.48}{92.9}$ & $\frac{40.54-0.26-15.50}{60.6}$ & $\frac{42.37-0.14-9.02}{58.7}$ & $\frac{0.67}{84.8}$ \\
\hline 02.2017 & $\frac{16.75-2.43-61.10}{92.2}$ & $\frac{40.12-0.25-15.18}{59.1}$ & $\frac{43.13-0.37-23.72}{69.2}$ & $\frac{0.67}{81.7}$ \\
\hline
\end{tabular}

Note: shl-q-s - scheelite-quartz-sulphide ore; shl-q-( $\left.\mathrm{P}_{\mathrm{x}} \mathrm{skarn}\right)-\mathrm{s}$ - scheelite-quartz-(skarn)sulphide ore; $P_{x}$ skarn - pyroxene skarn; skarn (amf) - hornfel-skarnified hornfels; bt metasomatite. - metasomatite-biotite hornfels; q metasomatite - quartz metasomatites.

The increment of scheelite distribution into diluting rock from main types of ores to $14.7 \%$ in February in relation to August, 2017 conditioned the drop of the expected extraction from feed with the $\mathrm{WO}_{3}$ content of $0.67 \%$ into finished concentrate by $3.1 \%$ (from $84.8 \%$ to $81.7 \%$ ).

\section{Conclusions}

The drop of scheelite extraction in current production ore from "Vostok-2" deposit is conditioned by several factors:

1. Greisen ore, with coarse scheelite grains, has become extremely rare and on the average is $2-2.5 \%$ of gross mass of scheelite-quartz ore. The percentage of easy scheelitequartz and scheelite-quartz-sulphide ores has reduced with growing redistribution of scheelite into diluting rocks.

2. The number of dispersed single scheelite grains in the volume of rock and anhedral grains in near-vein spaces adjacent to veins with high scheelite concentration, where complex associations of scheelite-biotite, scheelite-amphibole, scheelite-piroxene originate, has grown up.

3. The appearance of skarn minerals relicts and at times areas of skarn minerals in scheelite-sulphide ores which leads to formation, in the near-vein spaces, of scheelitepiroxene, scheelite-amphibole, scheelite-chlorite and scheelite-mica complex splices has been noted. Impregnations of scheelite have been found in quartzous rocks, the composition of mother rocks may be diverse (skarn, skarnified or biotite hornfels, quartzites).

4. The content of $\mathrm{CaCO}_{3}$ which is conditioned by the presence of Ca-containing minerals in the composition of skarns in the shape of thin (fine) grain crystalline impregnation along the crevices and cleavage faces with formation of thin microveinlets, often together with quartz has increased.

\section{References}

1. V.I. Gvozdev. Irkutsk, Publishing house of Institute of geography of Siberian division of Russian Academy of Sciences, materials of scientific conference, 1, 33-36 (2005).

2. V.I. Gvozdev. Vladivostok, Dalnauka, 31 (2010).

3. V.I. Gvozdev. Vladivostok, Dalnauka, 630-637 (2006). 
4. V.I. Gvozdev, Vladivostok, Dalnauka, 87-97 (2004).

5. L.A. Samatova, V.I. Gvozdev, L.A. Kienko and others. Pacific Geology journal, Khabarovsk city, 6, 83-96 (2006).

6. G.N. Stepanov, V.I. Gvozdev. New data on mineralogy of Far East, Far Eastern Russian Academy of the USSR, 49-55 (1987).

7. G.N. Stepanov. Mineralogy, petrogeny and genesis skarn-scheelite-sulphide deposits of Far East, M.: Nauka, 178 (1977).

8. G. N. Stepanov. Mineralogy and geochemistry of tungsten deposits, L.: Leningrad State University Publishing House, 234-242 (1971).

9. L. A. Samatova, E. D. Shepeta, V. I. Gvozdev. Physico technical problems of development of commercial minerals, Novosibirsk city, No.3, 152-161 (2012).

10. K. Nienhaus, T. Pretz, H. Wotruba, Sensor Technologies: Impulses for the Raw Materials Indusrty, Shaker Verlag, Aachen (2014).

11. T. Pretz, H. Wotruba, K. Nienhaus, Applications of Sensor-based Sorting in the Raw Material Industry, Shaker Verlag, Aachen (2011).

12. A. Haslam, Developments in the Tungsten Industry - Australia. 21-st ITIA Annual General Meeting, Xiamen, China (2008).

13. Report: "Experience with a sensor based sorting plant separating coarse scheelite ore" ITIA's 23rd Annual General Meeting, Vienna, Austria (2010).

14. L. A. Barskii, O. V. Kononov, L. I. Ratmirova. Selective flotation of calcium minerals, M.: Nedra, 232 (1979).

15. O.V. Konov, D.G. Koshut, I.V. Nesterov, Non-uniformity of minerals and nature of restricted isomorphism of scheelite-powellite, in the book of "Non-uniformity of minerals and crystal growth". M.: Nedra, 128-134 (1980).

16. A.A. Abramov, Kh. Khobert, Non-ferrous metals, 2, 26-34 (2008).

17. E.D. Shepeta, L.A. Samatova, V.A. Ignatkina. Ore beneficiation., 3,41-48 (2017). Research have been completed with the support of Russian Foundation for Basic Research grant No.17-05-00241\18". 